\title{
An assessment of the anatomical factor in cor pulmonale in emphysema
}

\author{
M. S. DUNNILL
}

From the Department of Pathology, the Radcliffe Infirmary, Oxford

\begin{abstract}
SYNOPSIS The morbid anatomical factors in the production of right heart hypertrophy and failure? in emphysema have been reviewed with reference to 44 cases studied by standard histologica $\not \subset$ methods and by post-mortem pulmonary arteriography. The most important factors in raising the pulmonary vascular resistance in these cases are considered to be vascular deformity and pressurfo by the emphysematous spaces on the adjacent branches of the pulmonary artery. Precapillaryo bronchopulmonary arterial anastomoses may be of importance in those cases where areas of localized bronchiectasis are present. Intimal fibrosis of the pulmonary arterioles, destruction of the pulmonary vascular bed, and thromboembolic phenomena were thought to be of only minok importance in the production of cor pulmonale in emphysema.
\end{abstract}

The term cor pulmonale is a somewhat nebulous one and before considering its pathogenesis an accurate definition is essential. The best definition is that given by Mack (1957). He states that 'chronic cor pulmonale may be defined as hypertrophy of the right ventricle resulting from disease involving the lung and/or pulmonary circulation. Failure of the right ventricle need not be present'.

The frequency of this condition is difficult to estimate. White and Brenner (1933) considered that it was rare and accounted for only $1 \%$ of patients with heart disease. Wood (1956) concluded that a conservative estimate of its frequency might be 5 to $10 \%$ of all cases of organic heart disease. Flint (1954), analysing 300 consecutive cases of congestive heart failure admitted to a general hospital in Sheffield, found cor pulmonale in 76 cases. Whatever the true figure an increase in the incidence of the disease would seem to be likely. Patients suffering from chronic bronchitis and emphysema now receive antibiotics and thus survive to die of heart failure at a later date. Similarly many more children and young adults survive acute pulmonary infections, and the importance of these acute infections in the production of chronic lung diseases in later life has been emphasized by McLean (1957). The use of antibiotics in pulmonary tuberculosis, with subsequent healing by fibrosis, and the increasing number of patients who undergo resection of pulmonary tissue with encroachment on their respiratory reserve, are all factors likely to lead to are increased incidence of right heart hypertrophy an failure secondary to lung disease.

The advent of cardiac catheterization, togethe $\frac{\mathscr{D}}{\mathrm{D}}$ with the observation of von Euler and Liljestrand? (1946) that anoxia produced a rise in pulmonary artery pressure, has tended to shift attention sharply away from the morbid anatomical lesions in righ? heart failure due to emphysema. This is unfortunate

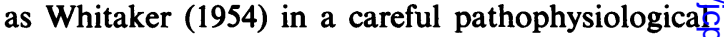
study of cor pulmonale showed that some factob other than anoxia, high cardiac output, and in 3 . creased blood viscosity was involved. Whitake favoured carbon dioxide retention as being o $B$ importance but this has not been substantiated. Io appears that the importance of the anatomica? lesions in this condition has been overlooked. This may be due to the absence of the dramatic histo $\overline{\bar{N}}$ logical findings, such as medial hypertrophy an $\$$ arteritis, seen in isolated histological sections in somf cases of pulmonary hypertension secondary tơ congenital or rheumatic heart disease.

The present paper is concerned with the findings in the pulmonary vessels as shown by conventionat histological techniques and by post-mortem pul@ monary arteriography. Arteriography gives ano overall picture of the pulmonary vascular tree in manner which is impossible by any other method The degree of structural damage to the pulmonary arterial system cannot be assessed even on the basif of numerous isolated blocks of lung tissue studiex by routine histological sections. If this is true of the 
lung in such conditions as primary pulmonary hypertension and mitral stenosis (Short 1956) it is even more the case in chronic lung disease where the changes are much more likely to be focal in nature.

\section{MATERIAL}

CASES STUDIED Forty-four cases coming to necropsy with the diagnosis of chronic bronchitis and emphysema have been examined. Details of the heart size and weight and the morbid anatomical type of emphysema (Ciba Symposium, 1959) from which the patients suffered are given in the accompanying Table. The thickness of the right ventricle was measured at the base and a measurement of $0.7 \mathrm{~cm}$. or greater was considered to denote hypertrophy. The left ventricle was taken to be hypertrophied if it measured $1.5 \mathrm{~cm}$. or more in thickness. All the patients complained of cough, expectoration of sputum, and breathlessness, and most of them died a respiratory death with an acute infection or congestive cardiac failure. Those dying from other causes are listed in the Table.

The thoracic organs were removed from the cadaver in one piece. Considerable care was taken not to puncture the lungs at any point and if necessary the parietal, as well as the visceral, pleura was removed. The heart was dissected from the lungs, the pulmonary veins being cut individually in their intrapericardial course but the pulmonary artery was left intact and was divided from the heart at a point just above the pulmonary valves.

\section{PULMONARY ARTERIOGRAPHY}

RADIO-OPAQUE MEDIUM A barium sulphate mixture (Micropaque) was used. The injection mass consisted of $75 \%$ Micropaque and $5 \%$ gelatin in water. The mixture was heated to, and kept at, a temperature of $75^{\circ} \mathrm{C}$.

TABLE

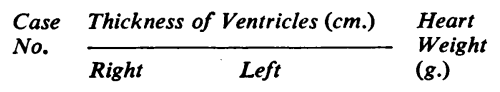

\begin{tabular}{|c|c|c|c|c|c|c|c|c|c|}
\hline $\begin{array}{l}1 \\
2 \\
3\end{array}$ & $\begin{array}{l}0.9 \\
0.7 \\
1.0\end{array}$ & $\begin{array}{l}1.4 \\
\text { Not recorded } \\
1.6\end{array}$ & $\begin{array}{l}540 \\
420 \\
520\end{array}$ & & + & + & + & & \\
\hline 4 & 0.9 & $2 \cdot 2$ & 850 & + & & & & & Systemic hypertension \\
\hline 5 & $1 \cdot 0$ & 1.4 & 520 & & + & & + & & \\
\hline 6 & 0.9 & $1 \cdot 2$ & 480 & & + & & & & \\
\hline 7 & 0.6 & 1.8 & 354 & & & + & & & \\
\hline 8 & 0.7 & $1 \cdot 6$ & 400 & & + & & & + & \\
\hline 9 & 0.5 & $1 \cdot 2$ & 400 & & + & & & & Myocardial infarct \\
\hline 10 & $1 \cdot 2$ & $1 \cdot 4$ & 300 & & + & & & & \\
\hline 11 & $1 \cdot 0$ & Not recorded & 324 & & + & & & & \\
\hline 12 & $1 \cdot 2$ & $1 \cdot 2$ & 320 & & & + & & & \\
\hline 13 & 0.8 & $1 \cdot \overline{5}$ & 540 & & + & & & & \\
\hline 14 & $1 \cdot 0$ & Not recorded & 530 & & + & & & & Myocardial infarct \\
\hline 15 & 0.8 & $2 \cdot 2$ & 536 & & + & & + & & Hypertension \\
\hline 16 & 0.8 & $1 \cdot \overline{8}$ & 440 & & + & & & & \\
\hline 17 & 0.6 & $1 \cdot 2$ & 260 & + & & & & & Head injury \\
\hline 18 & $0 \cdot 8$ & $1 \cdot \overline{8}$ & 340 & & & + & + & + & \\
\hline 19 & $1 \cdot 0$ & $1 \cdot 5$ & 530 & & + & + & & & \\
\hline 20 & 0.7 & $2 \cdot 1$ & 476 & & + & & & & Hypertension \\
\hline 21 & $1 \cdot 1$ & $2 \cdot 0$ & 450 & & + & + & + & & \\
\hline 22 & 0.8 & $1 \cdot 2$ & 380 & & & + & + & & \\
\hline 23 & $1 \cdot 0$ & $1 \cdot 2$ & 370 & & + & & & & \\
\hline 24 & 0.9 & $1 \cdot 4$ & 310 & & + & & + & & \\
\hline 25 & 0.8 & $1 \cdot 2$ & 540 & + & & & & & Myocardial infarct \\
\hline 26 & 0.4 & 1.6 & 420 & + & & & & & Head injury \\
\hline 27 & 0.8 & $1 \cdot 2$ & 402 & & + & & + & + & \\
\hline 28 & 0.7 & $1 \cdot 2$ & 410 & + & & & + & + & \\
\hline 29 & 0.4 & $1 \cdot \overline{3}$ & 360 & & + & & + & + & \\
\hline 30 & $1 \cdot 0$ & $1 \cdot 2$ & 382 & & + & & + & + & \\
\hline 31 & $1 \cdot 0$ & $1 \cdot 4$ & 500 & & + & & & + & \\
\hline 32 & 0.9 & $1 \cdot 4$ & 390 & & + & + & & & Haematemesis \\
\hline 33 & $1 \cdot 0$ & 1.4 & 480 & & & + & & & \\
\hline 34 & $0 \cdot 7$ & $1 \cdot 2$ & 290 & & + & & & + & Carcinoma of stomach \\
\hline 35 & $1 \cdot 0$ & $1 \cdot 8$ & 520 & & + & + & + & + & \\
\hline 36 & 0.6 & $1 \cdot 6$ & 362 & & + & + & & & Head injury \\
\hline 37 & 0.5 & $1 \cdot 2$ & 280 & & & & + & & Aspirin poisoning \\
\hline 38 & $1 \cdot 0$ & 1.6 & 500 & & + & + & & & \\
\hline 39 & 0.7 & 1.4 & 364 & + & & & + & & \\
\hline 40 & 0.8 & 1.6 & 416 & + & & & + & & \\
\hline 41 & 1.0 & 1.6 & 340 & & + & + & & + & \\
\hline 42 & 0.9 & $2 \cdot 0$ & 540 & & + & + & & & \\
\hline 43 & $1 \cdot 2$ & 2.0 & 650 & & + & + & + & + & \\
\hline 44 & 1.0 & $1 \cdot 5$ & 646 & & + & & & + & \\
\hline
\end{tabular}

Other than Respiratory

Causes

\begin{tabular}{lllll} 
Type of Emphysema & & & $\begin{array}{l}\text { Bronchiec- } \\
\text { tasis }\end{array}$ & $\begin{array}{l}\text { Cases Dying from } \\
\text { Other than Respiratory } \\
\text { Causes }\end{array}$ \\
\hline Bullous & $\begin{array}{l}\text { Centri- } \\
\text { lobular }\end{array}$ & $\begin{array}{l}\text { Paracinar } \\
\text { Destructive }\end{array}$ & $\begin{array}{l}\text { Associated } \\
\text { with Focal }\end{array}$ & \\
Fibrosis
\end{tabular}

\begin{tabular}{|c|c|c|}
\hline 1 & 0.9 & 1.4 \\
\hline 2 & 0.7 & Not recorded \\
\hline 3 & $1 \cdot 0$ & 1.6 \\
\hline 4 & 0.9 & $2 \cdot 2$ \\
\hline 5 & 1.0 & 1.4 \\
\hline 6 & 0.9 & $1 \cdot 2$ \\
\hline 7 & 0.6 & $1 \cdot 8$ \\
\hline 8 & 0.7 & 1.6 \\
\hline 9 & 0.5 & $1 \cdot 2$ \\
\hline 10 & $1 \cdot 2$ & $1 \cdot 4$ \\
\hline 11 & 1.0 & Not recorded \\
\hline 12 & $1 \cdot 2$ & $1 \cdot 2$ \\
\hline 13 & 0.8 & $1 \cdot \overline{5}$ \\
\hline 14 & 1.0 & Not recorded \\
\hline 15 & 0.8 & $2 \cdot 2$ \\
\hline 16 & 0.8 & $1 \cdot 8$ \\
\hline 17 & 0.6 & $1 \cdot 2$ \\
\hline 18 & 0.8 & 1.8 \\
\hline 19 & 1.0 & $1 \cdot 5$ \\
\hline 20 & 0.7 & $2 \cdot 1$ \\
\hline 21 & $1 \cdot 1$ & $2 \cdot 0$ \\
\hline 22 & 0.8 & $1 \cdot 2$ \\
\hline 23 & 1.0 & $1 \cdot 2$ \\
\hline 24 & 0.9 & $1 \cdot 4$ \\
\hline 25 & 0.8 & $1 \cdot 2$ \\
\hline 26 & 0.4 & 1.6 \\
\hline 27 & 0.8 & $1 \cdot 2$ \\
\hline 28 & 0.7 & $1 \cdot 2$ \\
\hline 29 & 0.4 & $1 \cdot 3$ \\
\hline 30 & 1.0 & $1 \cdot 2$ \\
\hline 31 & $1 \cdot 0$ & 1.4 \\
\hline 32 & 0.9 & 1.4 \\
\hline 33 & 1.0 & 1.4 \\
\hline 34 & $0 \cdot 7$ & $1 \cdot 2$ \\
\hline 35 & 1.0 & 1.8 \\
\hline 36 & 0.6 & 1.6 \\
\hline 37 & 0.5 & $1 \cdot 2$ \\
\hline 38 & $1 \cdot 0$ & 1.6 \\
\hline 39 & 0.7 & 1.4 \\
\hline 40 & 0.8 & 1.6 \\
\hline 41 & 1.0 & 1.6 \\
\hline 42 & 0.9 & $2 \cdot 0$ \\
\hline 43 & $1 \cdot 2$ & 2.0 \\
\hline 44 & 1.0 & $1 \cdot 5$ \\
\hline
\end{tabular}


before use. This medium penetrates to vessels of $0.03 \mathrm{~mm}$. diameter and gives a satisfactory image on the radiograph.

PREPARATION AND INJECTION OF LUNGS The method described by Short (1956) was used. The lungs were immersed in saline at $40^{\circ} \mathrm{C}$. for one hour before injection which was always carried out within three hours of removal from the body. This warming of the lung had the dual effect of relaxing the arteries and ensuring that the injection mass did not set until the fine vessels had been penetrated.

Post-mortem clot was removed by hand from the pulmonary arterial tree in the form of a 'mare's tail'. The pulmonary artery was then flushed gently with warm saline to remove further clot. Full-scale perfusion of the pulmonary artery with saline was not found to be necessary. A cannula with an attached polythene tube was then tied into the main pulmonary artery and the injection was made at a pressure of between 50 and $100 \mathrm{~mm}$. $\mathrm{Hg}$, the aim being to produce complete distension of the pulmonary arteries. The point at which the injection was complete was determined by watching the surface of the lung where the fine vessels in the secondary lobules could be seen through the thin parts of the visceral pleura. The injection mass never appeared in the pulmonary veins but the hilum of the lungs was watched carefully because reflux through the bronchial arteries was seen in cases of bronchiectasis. Histological evidence is needed before an arteriogram can be classed as satisfactory and the arteries said to be fully distended. In the uninjected lung the elastic laminae of the pulmonary arteries appear crenated but in the injected vessels the arterial wall appears much thinner and the elastic coats are smooth. An exception to this occurs when there is severe intimal fibrosis of the arteries which gives the vessels increased rigidity and prevents distension of the elastic laminae.

FIXATION AND RADIOGRAPHY Once the injection had been completed the pulmonary artery was ligated and the cannula removed. The trachea was then connected up to a reservoir containing $10 \%$ formol saline and the lung slowly distended with fixative under a pressure of $40 \mathrm{~cm}$. of water. The trachea was then clamped and the lungs immersed in a large bath of formol saline for three days. After this time the lungs were separated and each lung radiographed separately. The lung was then placed lateral (costal) side downwards on a wooden board fitted with Perspex runners, $1 \mathrm{~cm}$. deep, and cut into $1 \mathrm{~cm}$. thick slices using a specially made $17 \mathrm{in.} \mathrm{ham} \mathrm{knife.}$ These slices were than radiographed.

All radiographs were taken using a mobile Solus $x$-ray machine with attached transformer. Standard Kodak screen-type film was used without intensifying screens, the film being placed in a cardboard container. The anode-film distance was $80 \mathrm{~cm}$. For radiography of whole lungs an exposure of $10 \mathrm{sec}$. was used at Kv. 85 and Ma. 5. For radiographs of $1 \mathrm{~cm}$. slices an exposure of 4 sec. was used with Kv. 48 and Ma. 5 . All films were processed under standard conditions with four minutes in developer at $68^{\circ} \mathrm{F}$.

Finally, all the slices were examined carefully together with their corresponding radiographs and suitable block of tissue were selected for histological examination. A? least 20 blocks were taken from each lung. Sections were: stained by haematoxylin and eosin, orcein, van Gieson? and occasionally by the Masson trichrome method.

\section{RESULTS}

In most patients dying with chronic bronchitis an emphysema there is a multiplicity of pathologica findings in the lungs. Cases of pure centrilobular o $\overrightarrow{0}$ pure panacinar destructive emphysema are rare and. a mixed picture, with in addition some focal areas్ of fibrosis and areas of localized bronchiectasis, is nearly always found. It is for this reason that the term 'chronic non-specific lung disease' should $b \vec{\oplus}$ used. The histological appearances of a normal lun and of these various types of emphysema are illut strated in Figs. 1, 2, 3, and 4. Bullous emphysems provides an exception and in the present series there were four cases $(4,17,18$, and 19) where the emphy sema took the form of large bullae at the apices and along the anterior borders of the lungs. The rest of the lung parenchyma appeared normal (Fig. 5). It none of these cases was there congestive cardia $\vec{e}$ failure or right ventricular hypertrophy which could be attributed to the condition in the lungs. The pulmonary arteriograms in these cases were quit normal except for a mild degree of deformity in the region of the bullae. Unless bullae are exceptionalls large it is difficult to see how they can exert an 5 effect on the pulmonary artery pressure. In this connexion the report by Stevenson and Reid (1959) of unilateral obliteration of the pulmonary artery is interesting. Unfortunately, no pathological studies: have been made on their case but it seems mose likely that the right pulmonary artery had been completely compressed by a large bulla or group of bullae. Obviously if such a condition was bilatera? and sufficiently extensive, enough of the pulmonary vascular bed could be obliterated to cause congestive cardiac failure.

If the cases of pure bullous emphysema are excluded 40 cases remain and the findings in thesês are described below.

HISTOLOGICAL CHANGES IN THE VESSELS The maiñ pulmonary artery and the pulmonary trunk were studied in each case. Atheroma was present in evero case to a greater or lesser degree. It took the forn of focal fibrous thickening of the intima with areas where lipoid-containing macrophages were pro $\bar{D}$ minent. In some cases the intima was concentricall thickened with fibrous tissue. There was no obvious difference between those cases with right ventricula 8 hypertrophy and those without it. The media of these vessels showed an adult configuration of 

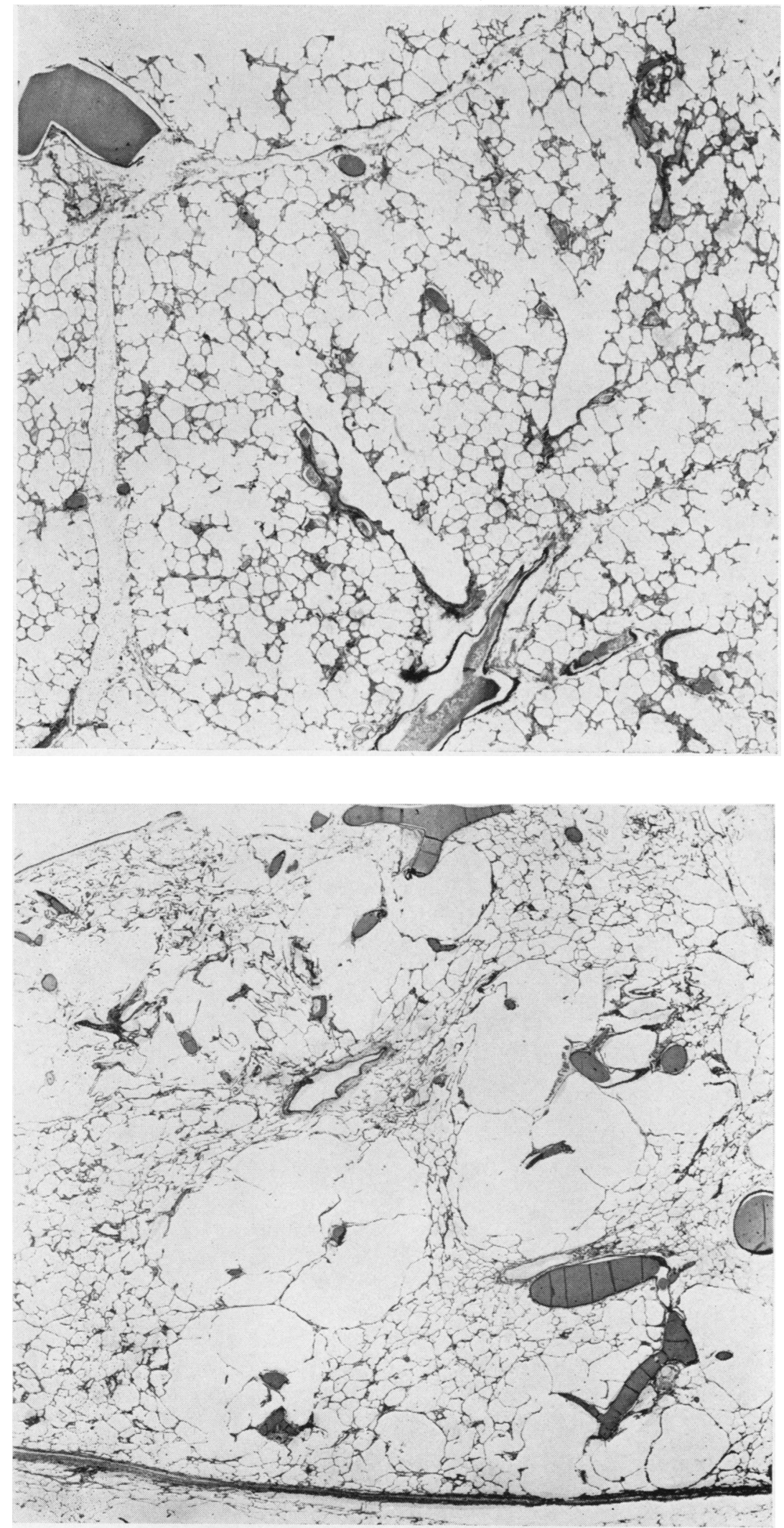

FIG. 1

FIG. 1. Normal lung showing a secondary lobule. Two terminal bronchioles can be seen which lead into respiratory bronchioles, alveolar ducts, and atria. Pulmonary artery injected. Orcein $\times 9$.

FIG. 2. Case 16. Centrilobular emphysema which is fairly extensive. The dilated emphysematous spaces can be seen in the centre of the lobules. Orcein $\times 6$.

FIG. 3. Case 33. Panacinar destructive emphysema. The large irregular air spaces extend throughout the entire secondary lobule. Orcein $\times$ 4.

FIG. 4. Case 28. Irregular emphysema in relation to a focal area of fibrosis which shows a mass of condensed elastic tissue. Orcein $\times 4$.

FIG. 5. Case 4. Bullous emphysema. Apart from apical bullae the lung is normal. Pulmonary artery injected.

FIG. 2 


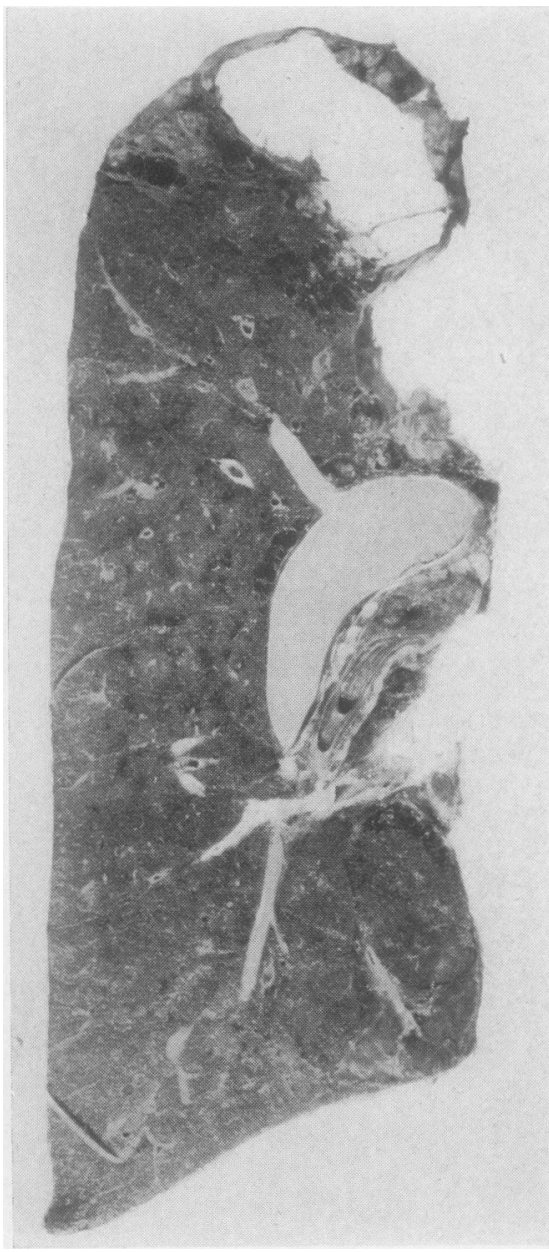

FIG. 3

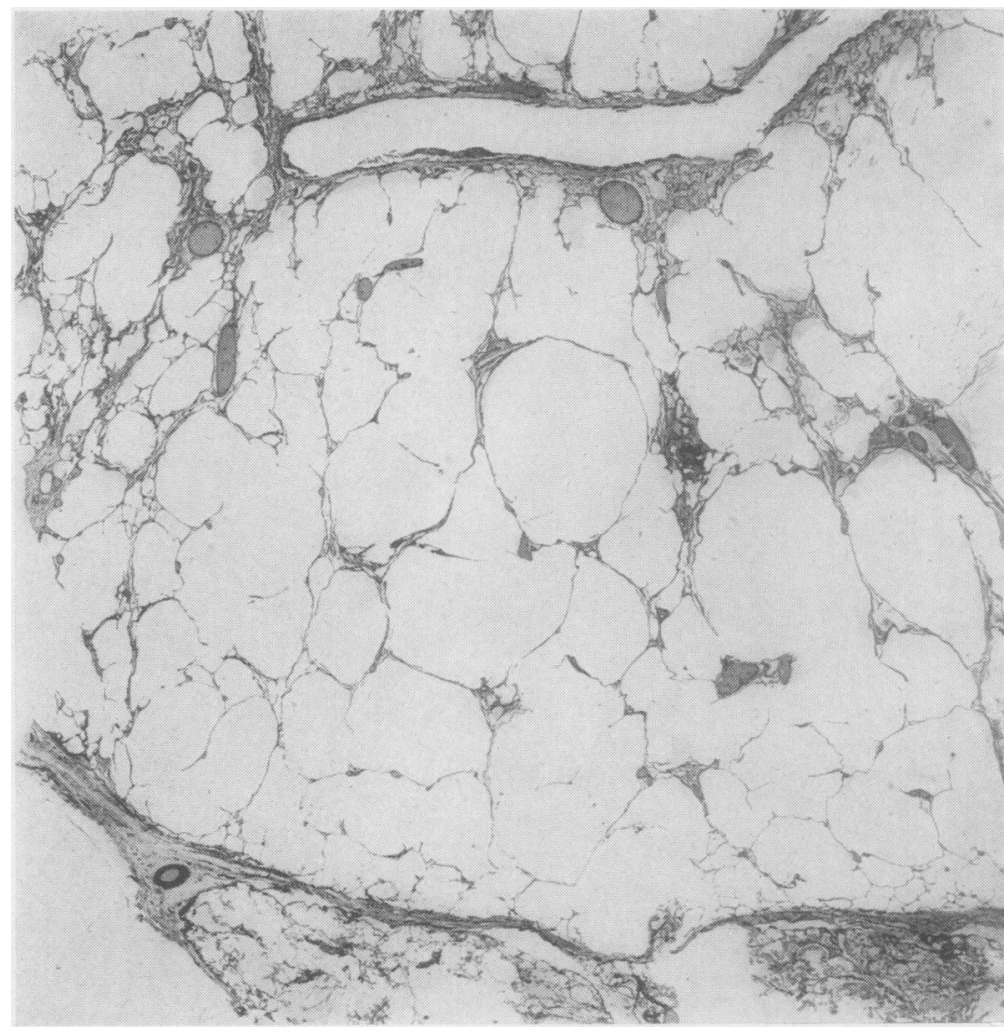

FIG. 5

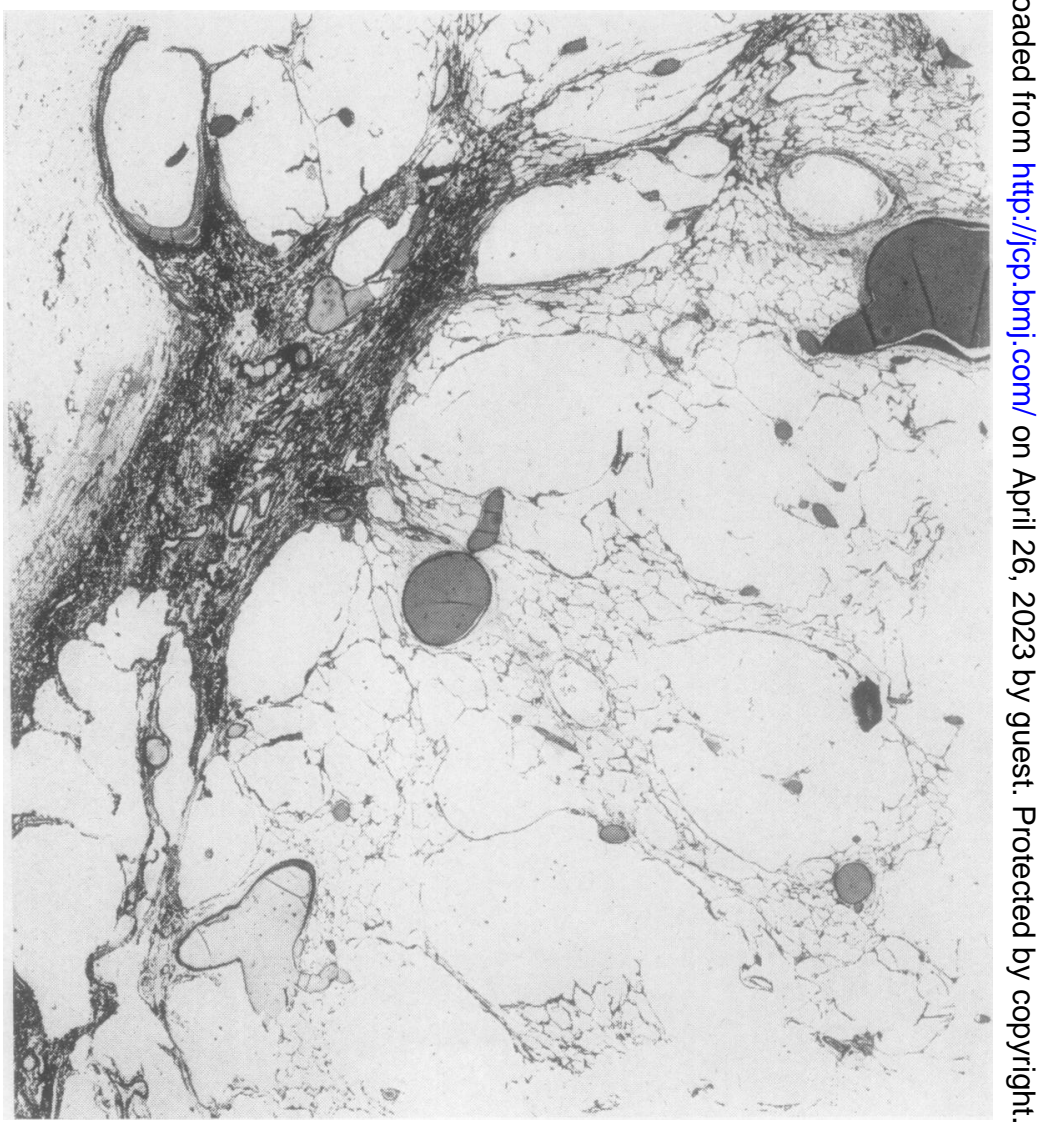




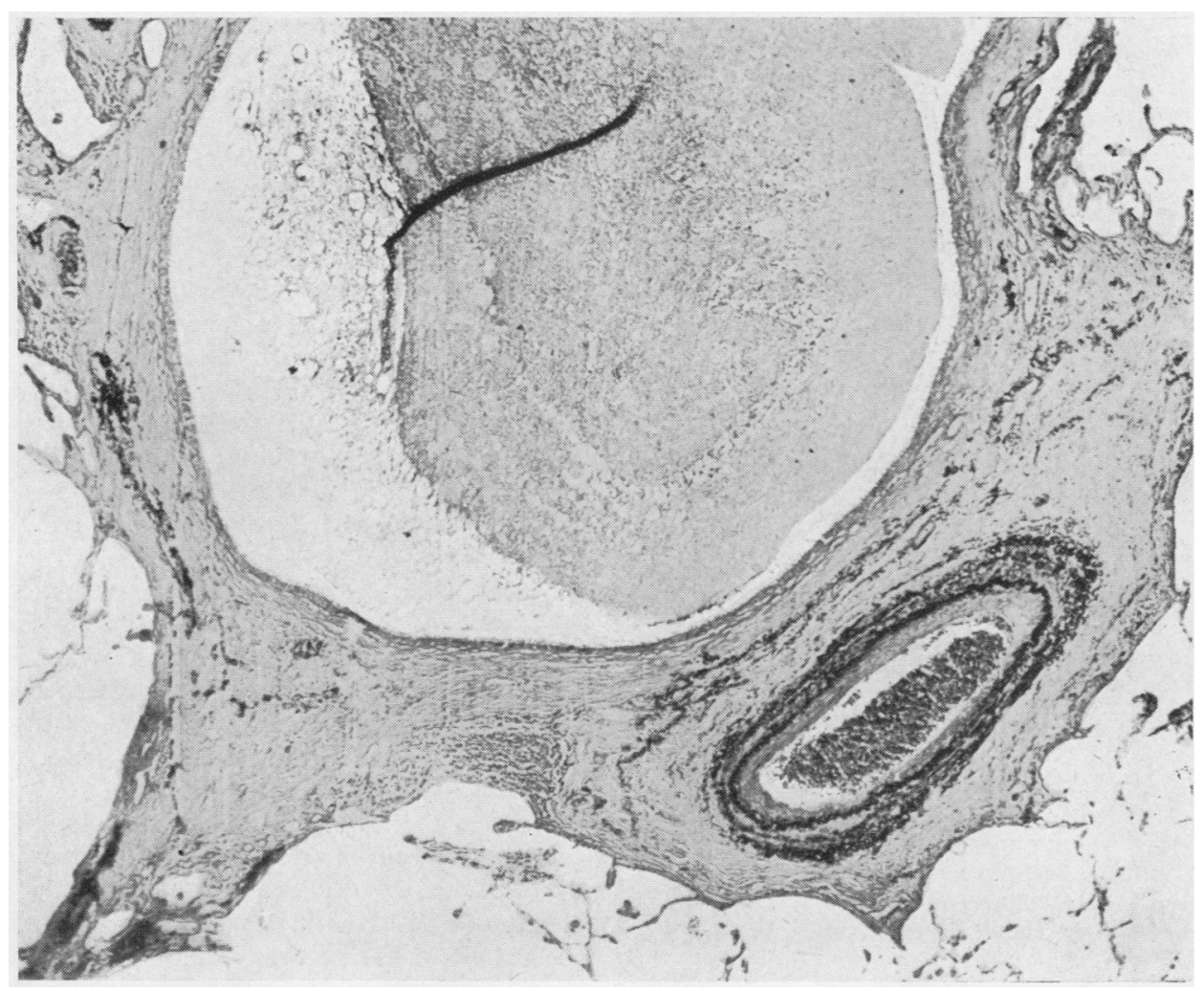

FIG. 6. Case 32. Intimal fibrosis in a muscular pulmonary artery adjacent to a dilated bronchiole filled with mucus. Uninjected specimen. Orcein $\times 80$.

elastic tissue; in no case was there anything approaching an aortic pattern. The most striking change was the amount of metachromatic material present in azur A preparations. In the cases with right ventricular hypertrophy this was greatly in excess of that seen in cases without right ventricular hypertrophy or in cases of the same age without lung disease.

The conducting or elastic arteries, vessels with an external diameter greater than $1 \mathrm{~mm}$., showed similar changes to those seen in the main pulmonary artery in the intima and media. In vessels showing atheroma it was interesting that the elastic laminae were frequently broken up by metachromatic material. In normal vessels of this size the elastic laminae are continuous in contrast to the interrupted laminae in the pulmonary trunk.

The muscular pulmonary arteries, vessels with an external diameter ranging from 1 to $0.1 \mathrm{~mm}$., show remarkably little change. Heath and Best (1958) were unable to detect any significant hypertrophy of the media in chronic lung disease even after an exhaustive series of measurements of the total area of the media and comparison with normal controls. Intimal fibrosis was a fairly common finding in muscular pulmonary arteries and was often seen in relation to adjacent diseased bronchioles (Fig. 6). Case 43 was unique in that it did show medial hypertrophy and fibrinoid necrosis in the muscular pulmonary arteries. It has been described fully elsewhere (Dunnill, 1960).

The pulmonary arterioles, vessels of less than $0.1 \mathrm{~mm}$. diameter, showed focal areas of intimal fibrosis in all cases (Fig. 10). This may well pass unnoticed in haematoxylin and eosin preparations but it is clearly apparent in sections stained for elastic tissue. This change is seen as an age phenomenon in normal lungs and so its significance is difficult to assess, but it was noticeable that it was more severe in relation to areas of emphysema.

ARTERIOGRAPHIC FINDINGS The following changes were seen on the arteriographs:-

Whole lung radiographs These are usually completely uninformative as to fine detail but they may 


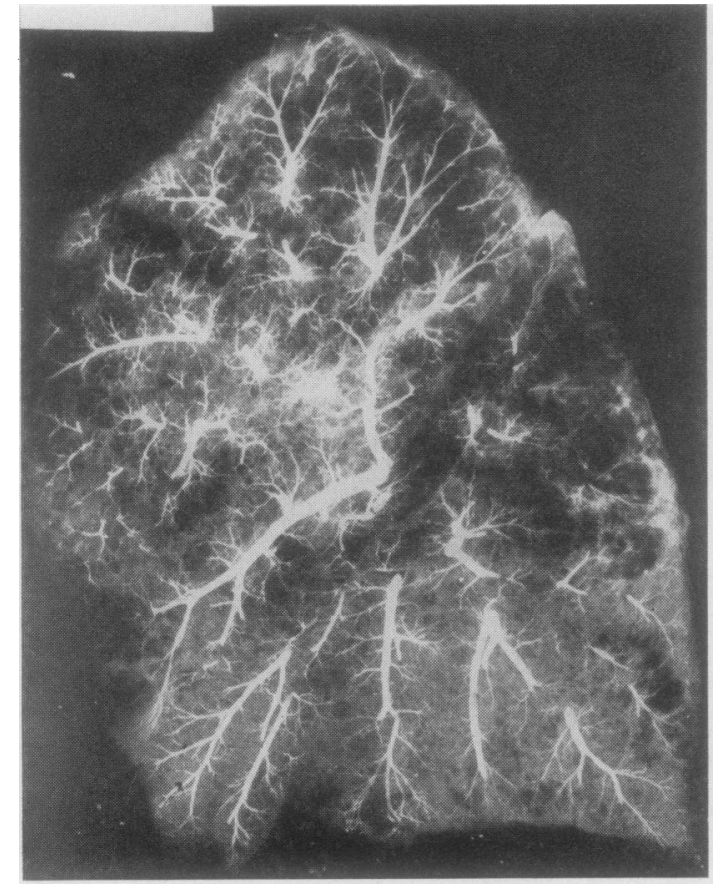

FIG. 7. Case 38. Post-mortem pulmonary arteriogram. Slice of lung $1 \mathrm{~cm}$. thick showing mixture of centrilobular and panacinar destructive emphysema with destruction of vascular bed. Compare with Fig. 8.

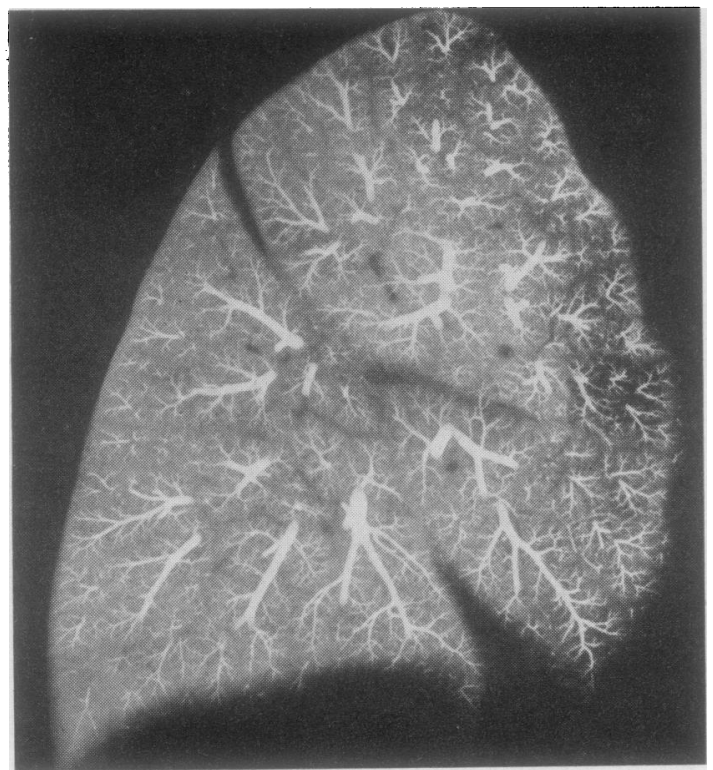

FIG. 8. Post-mortem pulmonary arteriogram in a man of 40 years with no cardiac or pulmonary disease. $1 \mathrm{~cm}$. slice. The filling defect at the base of the lower lobe is an artefact due to the presence of post-mortem clot. show compression and displacement of vessels by apical bullae. The most interesting feature and onethat is consistently present is the dilatation of the्ह large hilar, elastic pulmonary arteries when com: pared with those of a normal lung.

Destruction of pulmonary vascular bed This i the most obvious and most quoted change tha occurs in emphysema and it is best appreciated by examination of the radiographs of $1 \mathrm{~cm}$. thicks slices of lung (Fig. 7). In centrilobular emphysema $\vec{D}$ however, destruction of lung tissue may not be very extensive and while it is more so in panacinaf్ destructive emphysema the lung has such a large्ठ. anatomical and functional reserve that there i\$ seldom enough for this to be an important factor im $\vec{p}$ causing pulmonary hypertension and right hearfu failure.

Anastomotic channels The presence of precapil lary bronchopulmonary arterial anastomoses wa९ demonstrated in all the cases showing localized areas of bronchiectasis. The existence of thesळ anastomoses could often be deduced at the time of the injection by observing that the injection mass was flowing very freely from the cut ends of the bronchiat arteries at the hilum of the lung. In many instance numerous small blood vessels on the pleural surface of the lung, covering a bronchiectatic area, wer seen to be filled with the injection mass. The sub pleural region is an area where the bronchial an pulmonary circulations meet at a capillary level in the normal lung but in bronchiectasis these com? munications appear to be expanded and enlarged. The main anastomotic networks are, however, if the regions of the bronchiectatic spaces. They were seen most clearly in the radiographs of $1 \mathrm{~cm}$. lung slices but they could also be located on whole lun radiographs. If the diseased area was small the bronchial artery could be clearly visualized taking \& spiral course around the long axis of the bronchus in contrast to the pulmonary artery which rung roughly parallel to the bronchus. Where the diseast was more extensive the arrangement was disorderly: a whole segment or lobe being the seat of a corrs siderable network of communicating blood vessels.

In no case did the anastomoses occur in the forro of a large fistula between a single bronchial and $\mathbb{E}$ single pulmonary artery. The anastomoses tak place in the smaller vessels situated in the walls of the bronchiectatic sacs. In the normal lung there aro capillary communications between the two circula tions in the walls of the large bronchi. In localized acute bronchopulmonary infections the bronchia circulation undergoes considerable enlargement i⿱ the affected region. It seems likely, as suggested b Liebow, Hales, and Lindskog (1949), that during the formation of granulation tissue in such an area 


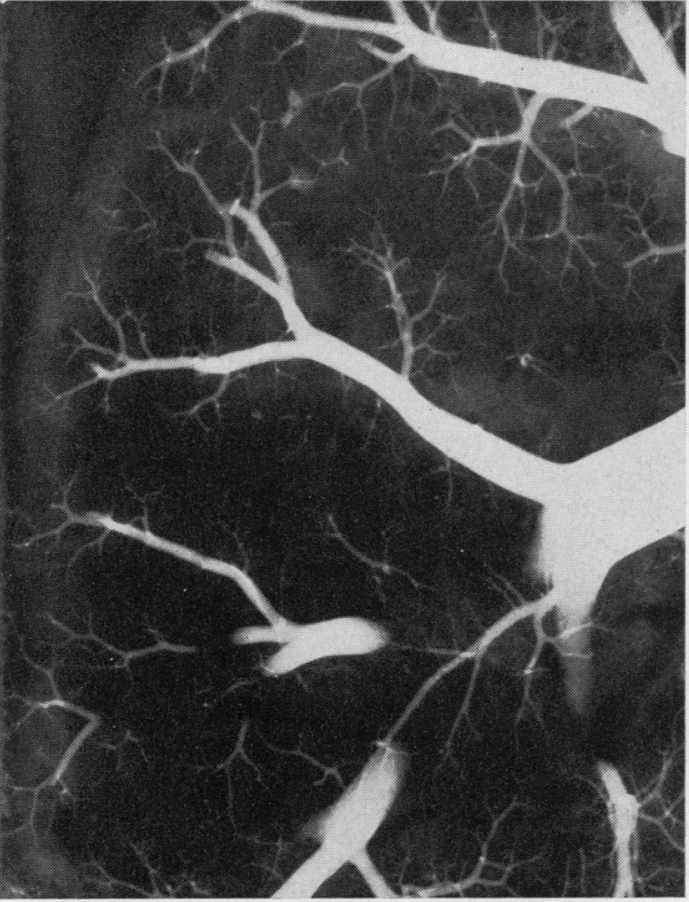

A

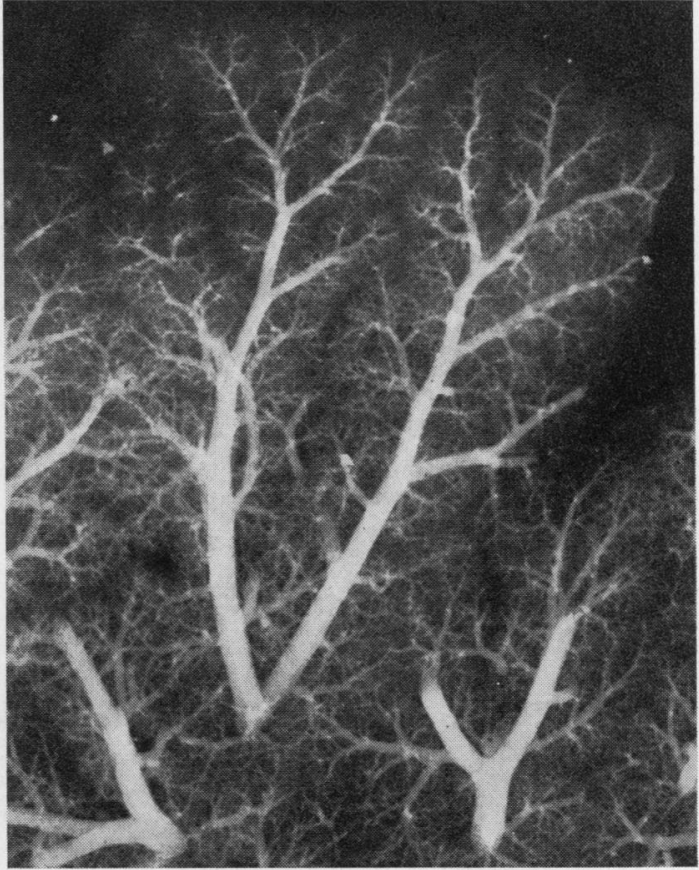

B

FIG. 9. A. Case 22. Close-up of $1 \mathrm{~cm}$. slice showing diffuse narrowing of small branches of the pulmonary artery in an area of panacinar destructive emphysema. B. Close-up of $1 \mathrm{~cm}$. slice of normal lung.

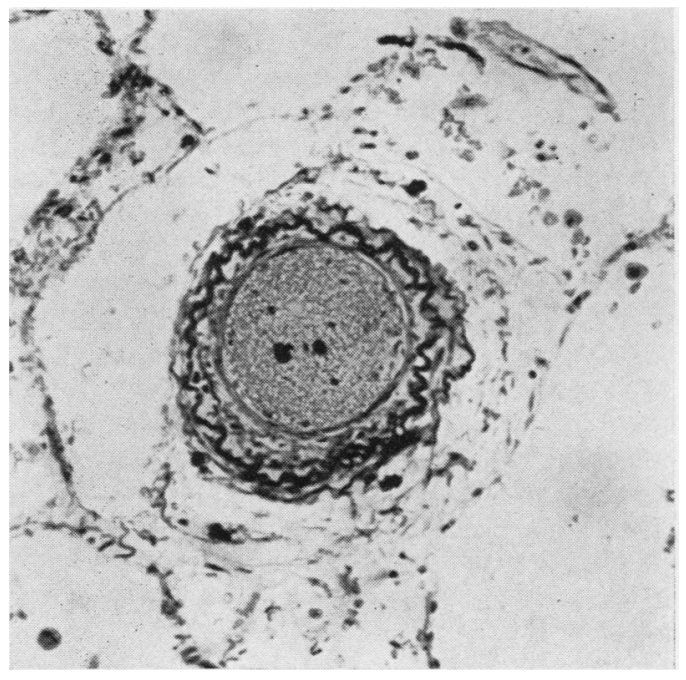

FIG. 10. Intimal fibrosis in a pulmonary arteriole. The injection mass has filled the lumen but the elastic lamina has maintained its corrugated appearance.

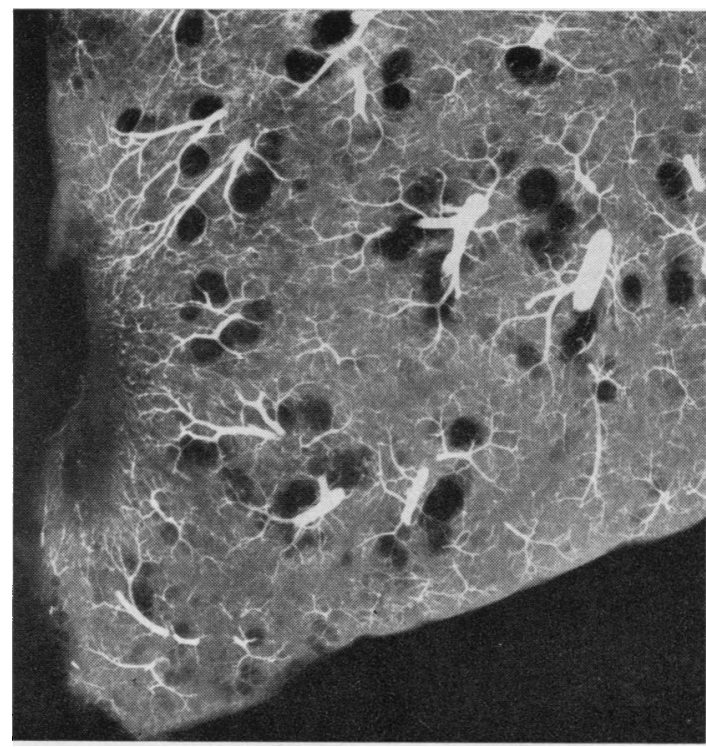

FIG. 11. Case 44. Deformity of pulmonary arterial branches in an area of centrilobular emphysema in $1 \mathrm{~cm}$. slice. At one border of the specimen there is an area of fibrosis without pulmonary arterial branches. 


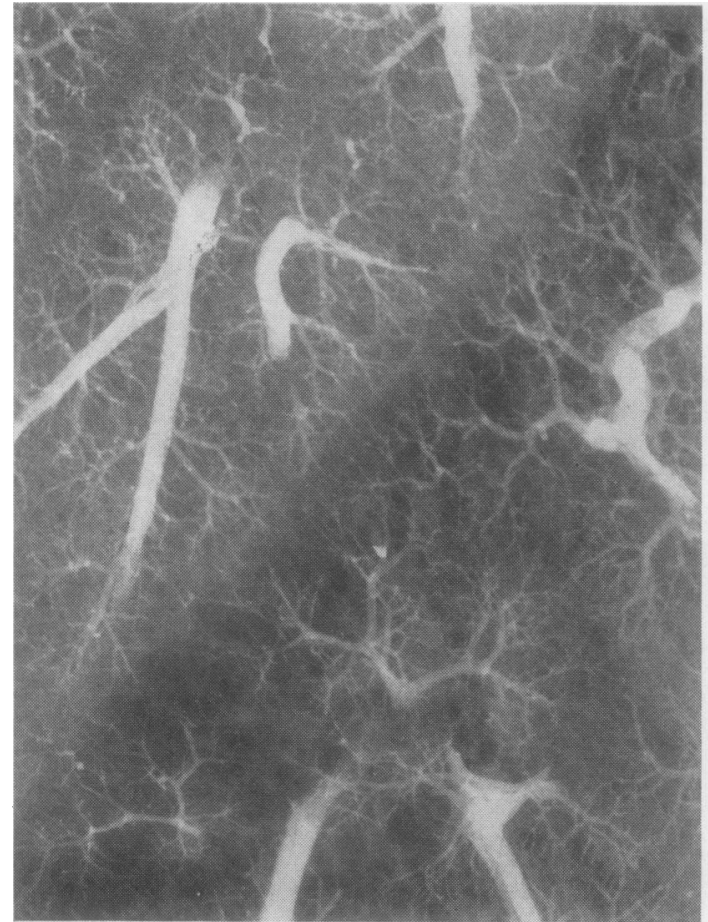

FIG. 12. Case 33. Close-up of $1 \mathrm{~cm}$. slice in an area of panacinar destructive emphysema. The disease is mainly in the lower lobe; the upper lobe is only slightly affected. The interlobar fissure passes across the centre of the picture.

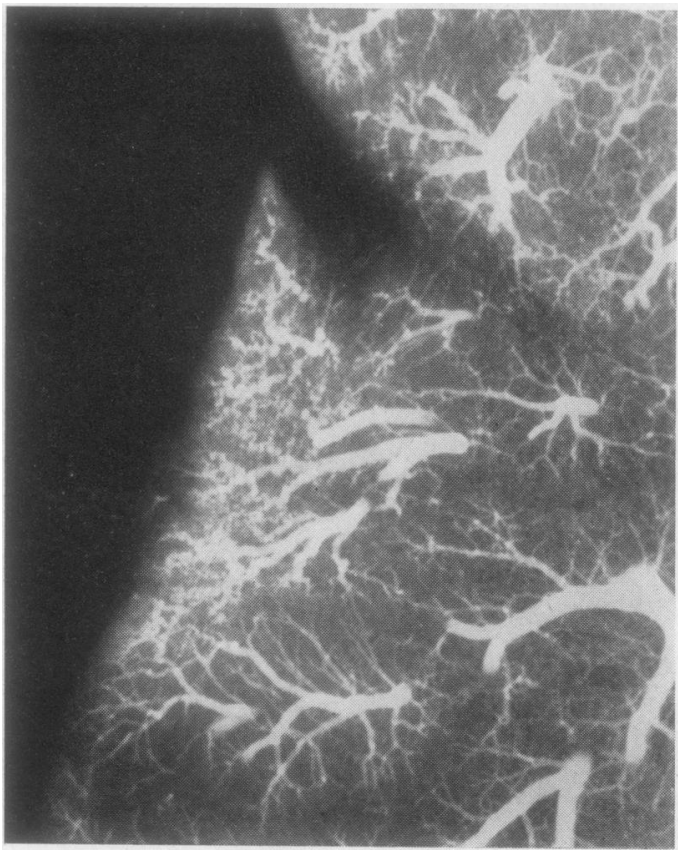

FIG. 13. Case 37. An area of fibrosis, seen in $1 \mathrm{~cm}$. slice of pulmonary arteriogram, showing the marked tortuosity of branches of the pulmonary artery. the two circulations may unite at precapillary level. The actual size of the communications joining two circulations is greater than $0.03 \mathrm{~mm}$. diameterer, beyond which the injection mass will not penetrafe, and usually less than $0.1 \mathrm{~mm}$. diameter.

Diffuse narrowing of arteries This change present in the small arterial branches in areas of emphysema. In radiographs of the whole lung( could be seen as a generalized pruning but it was best demonstrated in $1 \mathrm{~cm}$. thick slices (Figs. 8 and 9). Histological sections of such areas showed tkgt the vessels were fully distended but severely affect by intimal fibrosis (Fig. 10). The lumen was circupar and filled with injection mass but the surrounding elastic laminae were corrugated and obviously $n+6 \mathrm{t}$ stretched to capacity. This is due to the fact thet intimal fibrosis results in the arteriole becomigg rigid and non-distensible. Frequently there was ân 'avascular' area between one secondary lobule and the next. This appearance was due to the fact that the arterioles in these areas were narrowed to less than $0.03 \mathrm{~mm}$. diameter and thus failed to fill wh the injection mass.

Areas of centrilobular emphysema These particularly well shown in pulmonary arteriograms (Fig. 11). They are situated at the point where tee artery supplying the secondary lobule bifurcatis, the emphysematous space being situated in the fo $\$$ k formed by the two branches. The effect of this the vessel will depend to some extent on the sige of the emphysematous space but even in areas where it is relatively small the adjacent arteries will fe deformed. The centrilobular emphysematous space is situated at a key point with reference to the arterial supply to the secondary lobule. If the pressufe within the emphysematous space rises the sưgrounding vessels will be compressed and have 90 pursue an abnormally circuitous course to the rest of the lobule.

윽

Areas of panacinar destructive emphysema Tfe main arteriographic feature is one of thin spidery arteries which appear much more widely separated than in a normal lung (Fig. 12). The difference is, however, greater than this because in addition vegy few small branches come off these vessels. This is 40 be expected from the histological nature of the lesici. The arteriogram represents a combination of paremchymal destruction, with corresponding obliteration of the vascular bed, and intimal fibrosis in the remaining vessels.

Areas of fibrosis Two quite distinct types vascular pattern were seen in areas of fibrosis. $\Phi_{n}$ the first type, which was more frequent, there ws a marked degree of tortuosity in the muscular pulmonary arteries and aterioles. This was an arresting finding in the arteriograms (Fig. 13). Foge 


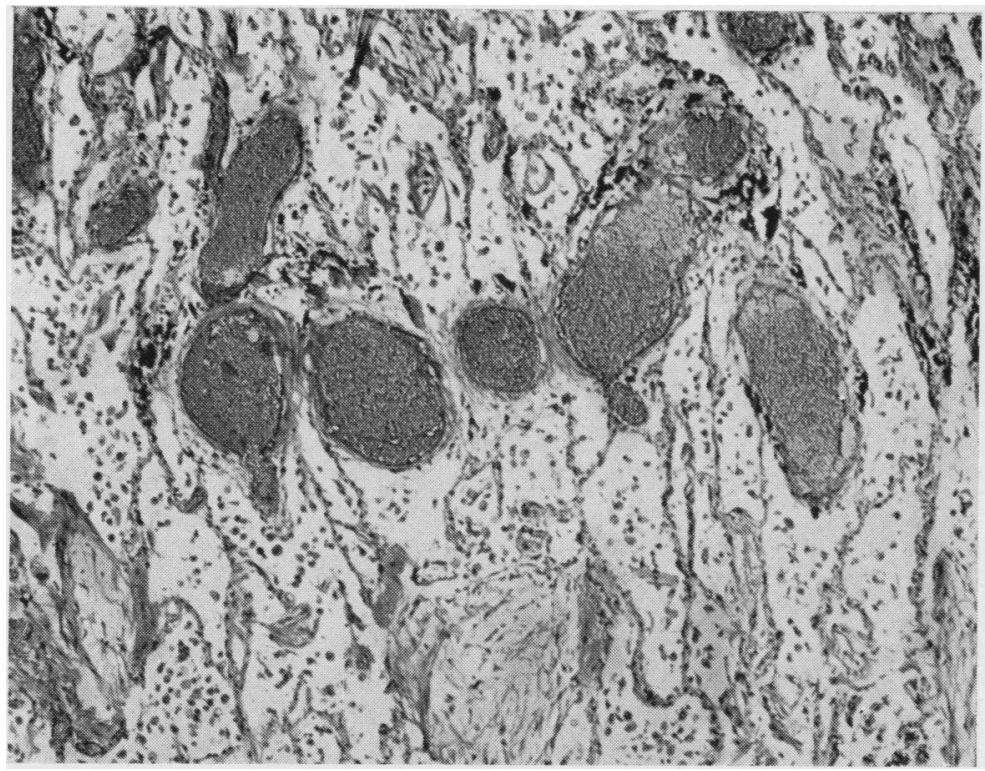

FIG. 14. Case 37. Photomicrograph of an area of organizing pneumonia and early fibrosis. The pulmonary arterial branches are very tortuous and in a single section one vessel appears many times. Haematoxylin and eosin $\times 50$.

histological appearance of these lesions, which were sometimes related to areas of emphysema, depended on their age. A recent lesion appeared as a focus of organizing pneumonia with somewhat shrunken alveoli filled with plump fibroblasts and a few chronic inflammatory cells. In a single histological section of such an area any given artery may appear several times (Fig. 14) thus giving the illusory appearance of increased vascularity. In an older lesion the vascular pattern remains similar but the histology alters because fibrosis is more advanced and the most prominent feature is the dense aggregation of elastic fibres which outline the collapsed alveolar pattern. In this type of lesion the vessels still appeared tortuous but there was very considerable luminal narrowing due to fibrous intimal proliferation.

The second pattern in areas of fibrosis was one of simple avascularity as far as the pulmonary arteriograms were concerned (Fig. 11). The surrounding vessels were thin and tapering. Histology of such an area showed hyaline fibrous tissue surrounded by lymphocytes. Occasionally a giant cell of the Langhans type could be seen and it is probable that these areas, which are not common, represent old tuberculous lesions. This would be in keeping with the views of Cudkowicz (1952) who found that tuberculous lesions frequently gained their blood supply from the bronchial as opposed to the pulmonary circulation.

Antemortem thrombus in branches of pulmonary artery This was a finding in 16 cases. In 12 cases thrombus was found in the femoral veins or deep calf veins at necropsy but in the remaining four cases no systemic venous thrombosis was detected at all. Gross examination of the lung slices in conjunction with the arteriograms showed thrombus in the elastic pulmonary arteries in 10 cases. In the further six cases thrombus was found in the muscular pulmonary arteries when the lungs were examined histologically. It must be assumed that in those cases where leg vein thrombosis was present the thrombus found in the pulmonary arterial branches was embolic in origin. In the four cases where no leg vein thrombosis was found it seems most probable that there was a thrombosis in the small pulmonary arterial branches which took place as a reaction to the adjacent inflammatory reaction in the bronchioles and pulmonary tissue.

In three cases there was evidence of pulmonary infarction. The reason for this is not fully apparent as in none of these cases was the thrombus particularly large nor did the affected lung suffer from chronic passive venous congestion. However, Torack (1958) described pulmonary infarction occurring in the absence of congestion due to heart disease where there was pleural effusion, pneumonia, pulmonary collapse, or bronchial occlusion. In all three cases showing infarction there was coexistent acute pulmonary infection and this was probably the important factor.

\section{DISCUSSION}

The syndrome of "chronic bronchitis and emphysema' is the commonest and most important cause 
of cor pulmonale in Great Britain. The factors involved in the pathogenesis of this condition can be divided into disturbances of physiology, such as anoxia, carbon dioxide retention, and polycythaemia, and disturbances in the anatomical structure of the lung and pulmonary circulation. While it is realized that the first group of factors is very important it is with the second group that this discussion is concerned.

INTIMAL FIBROSIS OF ARTERIES AND DESTRUCTION OF PULMONARY VASCULAR BED The normal pulmonary vascular bed is capable of an extreme degree of distensibility. Thus in a normal subject the pulmonary blood flow of approximately 5 litres a minute at rest can be increased to values as high as 25 or 30 litres a minute during exercise with little or no increase in pulmonary artery pressure. Factors decreasing this distensibility are of importance in the production of cor pulmonale. It is usually claimed that intimal fibrosis in the arterioles, destruction of the capillary bed, and parenchymal fibrosis are the three most important lesions in this respect. The significance of intimal fibrosis of the arterioles is in dispute. That such lesions occur and are frequent is not doubted but what part they play in raising the pulmonary artery pressure is debatable. Evans (1951) considers them all important. However, intimal fibrosis has been described as a normal age phenomenon in adults with no evidence of cardiac or pulmonary disease by Welch and Kinney (1948) and Civin and Edwards (1951), and, although it may be more extensive in cases of emphysema (McKeown, 1952), the difference is not enough to account for right ventricular hypertrophy. The origin of the intimal fibrosis is unknown. It may represent organized mural thrombus, and McLean (1958) has pointed out that there is a close topographical relationship between sclerotic arterial lesions and lung tissue showing chronic inflammatory damage. In particular he observed that sclerosis was much more striking in arteries adjacent to diseased bronchioles and he concluded that in many cases this intimal fibrosis represented organization of mural thrombus which had formed as a reaction to past acute inflammation. In general it may be concluded that these sclerotic arterial changes in emphysema are never sufficiently widespread or advanced to cause pulmonary hypertension on their own account. They differ too little from the normal age change and their distribution is too localized.

Mack (1957) considers that destruction of the pulmonary vascular bed by conversion of small air spaces into fewer larger spaces with destruction of alveolar septa and loss of capillaries is important in the production of cor pulmonale in emphysema. However, before there is any rise in pulmonary artery pressure there must be a considerable degree $\stackrel{\stackrel{0}{\vec{\sigma}}}{\underline{\sigma}}$ of destruction of pulmonary tissue. Flores, Adams, and Perkins (1954) reduced the pulmonary arterial $\stackrel{5}{\rightarrow}$ tree of dogs to $15 \%$ of normal without producing pulmonary hypertension at rest though they did find a rise in pressure on exercise. In clinical practice $\frac{\bar{c}}{\frac{\sigma}{\sigma}}$ numerous patients have undergone resection of $a \stackrel{\Phi}{\Omega}$ lung without developing pulmonary hypertension, at least during a short-term follow-up. Motley (1959) has found that pulmonary heart disease may develop $\stackrel{\circ}{\circ}$ in the older age groups after a latent period of $\overrightarrow{\vec{\omega}}$ several years during which regular work and activity $\stackrel{\sim}{\omega}$ have been carried out. He considers that heart $\overline{0}$ failure in these cases is due to the over-distension of the remaining lung which takes place to fill the space $\vec{\omega}$ left by the tissue which has been removed, and that in the condition can be prevented by thoracoplasty. $\vec{\sigma}$

In the various forms of emphysema destruction of 0 the pulmonary vascular bed probably plays a minor rôle in the pathogenesis of cor pulmonale. In many 3 cases of centrilobular emphysema with right ventricular hypertrophy the pulmonary destruction is $\vec{\varphi}$ confined to the centre of the secondary lobules, the $\stackrel{\circ}{\rightarrow}$ alveoli at the periphery being relatively normal. In panacinar destructive emphysema the degree of 0 destruction of the vascular bed is more striking but it is seldom enough to force one to conclude that it is a major factor in raising pulmonary vascular $\stackrel{\mathscr{Q}}{\not}$ resistance when it is remembered that, if an analogy $\cong$ can be drawn from experimental work, over $80 \%$ of $\overrightarrow{\overrightarrow{0}}$ lung tissue would have to be destroyed.

AREAS OF FIBROSIS Focal areas of fibrosis are common in chronic non-specific lung disease. Numerous authors (Mack, 1957; Motley, 1959; Spain, 1959) imply that in areas of pulmonary fibrosis there is 3 . vascular obliteration with narrowing of the vessels due to contraction of surrounding fibrous tissue. This may be seen in a few areas but more commonly the areas of fibrosis contain branches of the pulmonary artery that are most remarkable for their $\frac{D}{0}$ tortuosity. This phenomenon of vascular deformity with increased tortuosity as a factor in raising $N$ pulmonary vascular resistance was emphasized by $N$ Patel and Burton (1957). They found deformity orN 'gnarliness' of the pulmonary arterial branches in ${ }_{\sigma}^{\omega}$ rabbits following the injection of norepinephrine and they considered it to be a major factor in raising the pulmonary vascular resistance and thus the pulmonary artery pressure. Similarly Reynolds (1956) $)_{+}^{+}$ has shown that in guinea-pigs the raised pulmonary vascular resistance during foetal life could be corre- $\overrightarrow{\mathrm{D}}$

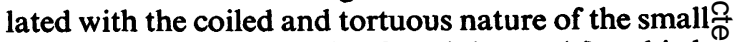
pulmonary vessels in the foetal lung. After birth when the pulmonary vascular resistance falls dramatically these vessels uncoil and become straight. 
Clearly in emphysema the areas of fibrosis with their tortuous vessels are of no great importance in raising the pulmonary vascular resistance as a whole unless they are very extensive. Their main importance lies in the fact that they raise the resistance locally to pulmonary blood flow thereby serving to divert blood away from the fibrotic areas to the more normal parts of the lung where oxygenation can take place.

AREAS OF LOCALIZED BRONCHIECTASIS The significance of precapillary bronchopulmonary arterial anastomoses in the production of right ventricular hypertrophy in bronchiectasis has been fully discussed by Liebow et al. (1949). These anastomoses raise the pulmonary artery pressure and increase the work of the right ventricle, because the pressure in the bronchial arteries is related to the pressure in the aorta and is therefore higher than that in the pulmonary artery. In the cases discussed here the areas of bronchiectasis were small and localized and probably played only a minor rôle in the production of right ventricular hypertrophy. It is interesting to note that Spain (1959) considers that cor pulmonale does not occur in bronchiectasis unless the disease is diffuse, bilateral, and accompanied by emphysema.

It should be noted here that no attempt has been made in this series of cases to demonstrate the bronchopulmonary venous anastomoses described by Liebow (1953) in cases of emphysema. It appears that most of his patients suffered from bullous emphysema rather than one of the more diffuse varieties of the disease.

THROMBO-EMBOLISM Thrombo-embolic phenomena are common in the pulmonary arteries of patients with pulmonary emphysema. There is little evidence, however, that they play a major part in the production of pulmonary hypertension in this condition. Kernen, O'Neal, and Edwards (1958) reviewed the incidence of pulmonary arteriosclerosis and thrombo-embolism in emphysema. They concluded that neither could be an important factor in the pathogenesis of pulmonary hypertension with chronic emphysema since the incidence of both pulmonary arteriosclerosis and thrombo-embolism was the same in cases of emphysema with right ventricular hypertrophy and without right ventricular hypertrophy.

AREAS OF CENTRILOBULAR EMPHYSEMA Leopold and Gough (1957) in their original communication on the centrilobular form of emphysema noted that right ventricular hypertrophy was present in over half their cases. In the present series of cases the relationship was even more marked. The explanation for the right ventricular hypertrophy in these cases is not at once apparent. In many instances the destruction of the vascular bed is not great, the areas of emphysema being confined to the centre of the lobule, fibrosis is not a prominent feature, and the degree of intimal thickening in the small branches of the pulmonary artery is not enough to account for the cardiac hypertrophy. A possible answer is to be found in the pulmonary arteriograms. Attention has been drawn to the fact that centrilobular emphysematous spaces are often situated at the bifurcation of the muscular pulmonary arteries supplying the secondary lobules. The arteries instead of pursuing a straight course curve around the emphysematous space bringing in an element of vascular deformity. Probably the most important factor in these cases is the pressure of the emphysematous space itself on the adjacent artery. In considering resistance to flow in arteries pressure on the vessels from without is usually ignored, attention being focused almost entirely on thrombus in the lumen and intimal fibrosis and medial hypertrophy in the wall. In emphysema, where medial hypertrophy is seldom if ever present and thrombus and intimal fibrosis are insufficient to account for the cardiac changes, it may well be that this extravascular factor is all important. Spain and Handler (1946) considered that intra-alveolar pressure on the pulmonary capillaries was important but they appear to have given little attention to the arteries.

Physiological studies bear out the importance of intra-alveolar pressures on pulmonary blood flow. Bjurstedt and Hesser (1953) showed that in dogs during inspiration the output of the right heart increases and there is an increase in pulmonary artery pressure. García Ramos (1955) found that in normal animals the pulmonary capillaries were flattened during inspiration and this has been thought to be the explanation for the increase in pulmonary vascular resistance during this phase of the cycle. Riley (1959), using isolated lung preparations, showed that there was an increase in resistance to pulmonary blood flow during lung inflation. In emphysema the findings are somewhat different. Attinger, Goldstein, and Segal (1956) and Dekker (1958) have demonstrated clearly that in emphysema expiration is very prolonged with the production of a markedly positive intra-alveolar pressure. The measurement of absolute values is subject to error due to technical difficulties but it is possible for values of at least $40 \mathrm{~cm}$. of water to be sustained during expiration. Such pressures when exerted on the smaller branches of the pulmonary artery will easily cause compression and occlusion; the pressure in the main pulmonary artery does not reach these levels during health. Although such a pressure is only intermittently exerted it must be remembered that in emphysema, where the expiratory part of 
the cycle may be as much as five times as long as the inspiratory component, the vessels will be subject to this extramural pressure for a very considerable time. Furthermore during the expiratory phase blood will still be pumped into the lungs and, if it cannot penetrate to the alveolar capillaries, the elastic, conducting pulmonary arteries will dilate. This dilatation of the larger pulmonary arteries has been noted in this series and also by Harrison (1958) and Meessen (1959).

One of the interesting facts about the pulmonary artery pressure in emphysema is that it is often normal or only slightly raised when the patient is not in cardiac failure. In failure this pressure rises considerably but is not due entirely to anoxia (Whitaker, 1954) although attacks of congestive failure are frequently precipitated by acute pulmonary infections. During such an infection it is the bronchioles which are most severely affected with peribronchiolar inflammation and exudation of mucus and pus into the lumen of the air passages. It is this type of exudate that may well constitute a ball-valve obstruction, air entering the peripheral lung with powerful inspiration but expulsion of the air being difficult with weaker expiration. The intraalveolar pressure will rise and will be felt particularly by the weakened centrilobular spaces rather than the relatively normal and more distal alveoli. Furthermore this raised pressure will be transmitted to the surrounding branches of the pulmonary artery, serving to raise the resistance in these vessels.

The situation of the centrilobular emphysematous spaces near the apex and in the centre of the secondary lobule is important. It is at the apex that the arterial supply enters the lobule, thus pressure on the vessels at this point will be most effective in raising resistance to blood flow in the whole area of the lobule. Probably it is because of this that in many cases of widespread centrilobular emphysema, in which many lobules are affected to a minor degree, right ventricular hypertrophy is present. There may be little parenchymal destruction but that which is present occurs at a vital point.
I am grateful to Miss Margaret Reading for technical assistance. Dr. T. M. Parry took the photographs. Dr. F. H. Kemp has kindly allowed me free access to the radiological department of the Radcliffe Infirmary. Finally, I must acknowledge the helpful advice and encouragement I have received from Dr. A. H. T. Robb-Smith throughout the course of this work.

\section{REFERENCES}

Attinger, E. O., Goldstein, M. M., and Segal, M. S. (1956). Amer. Rev. Tuberc., 74, 210.

Bjurstedt, H., and Hesser, C. M. (1953). Acta physiol. scand., 29, 180. Ciba Symposium (1959). Thorax, 14, 286.

Civin, W. H., and Edwards, J. E. (1951). A.M.A. Arch. Path., 51, 192.

Cudkowicz, L. (1952). Thorax, 7, 270.

Dekker, E. (1958). Thesis. University of Groningen. Le Noble and Bronder, Amsterdam.

Dunnill, M. S. (1960). Brit. J. dis. Chest, 54, 355.

Euler, U. S. von, and Liljestrand, G. (1946). Acta physiol. scand., 12, 301 .

Evans, W. (1951). Proc: roy. Soc. Med., 44, 600.

Flint, F. J. (1954). Lancet, 2, 51.

Flores, A., Adams, W. E., and Perkins, J. F. (1954), A.M.A. Arch. Surg., 68, 627.

Garcia Ramos, J. (1955). Amer. Rev. Tuberc., 71, 822.

Harrison, C. V. (1958). Brit. J. Radiol., 31, 217.

Heath, D., and Best, P. V. (1958). J. Path. Bact., 76, 165.

Kernen, J. A., O'Neal, R. M., and Edwards, D. L. (1958). A.M.A. Arch. Path., 65, 471.

Leopold, J. G., and Gough, J. (1957). Thorax, 12, 219.

Liebow, A. A. (1953). Amer. J. Path., 29, 251.

- Hales, M. R., and Lindskog, G. E. (1949). Ibid, 25, 211.

Mack, I. (1957). In Clinical Cardiopulmonary Physiology (American College of Chest Physicians), p. 480, ed. Gordon, B. L. Grune and Stratton, New York.

McKeown, F. (1952). Brit. Heart J., 14, 25.

McLean, K. H. (1957). Aust. Ann. Med., 6, 29.

(1958). Ibid, 7, 69.

Meessen, H. (1959). Acta cardiol. (Brux.), 14, 211.

Motley, H. L. (1959). Progr. cardiovasc. Dis., 1, 326.

Patel, D. J., and Burton, A. C. (1957). Circulat. Res., 5, 620.

Reynolds, S. R. M. (1956). Amer. J. Anat., 98, 97.

Riley, R. L. (1959). In Pulmonary Circulation: An International Symposium, 1958. p. 147. (Chicago Heart Association), ed. Adams, W. R., and Veith, I. Grune and Stratton, London.

Short, D. S. (1956). J. Fac. Radiol., 8, 118.

Spain, D. M. (1959). In Pulmonary Circulation, p. 99, ed. Adams, W. R., and Veith, I. Grune and Stratton, London. - , and Handler, B. J. (1946). Arch. intern. Med., 77, 37.

Stevenson, J. G., and Reid, J. M. (1959). Thorax, 14, 82.

Torack, R. M. (1958). A.M.A. Arch. Path., 65, 574.

Welch, K. J., and Kinney, T. D. (1948). Amer. J. Path., 24, 729.

Whitaker, W. (1954). Quart. J. Med., 23, 57.

White, P. D., and Brenner, O. (1933). New Engl. J. Med. 209, 1261. Wood, P. H. (1956). Diseases of the Heart and Circulation, 2nd ed., p. 849. Eyre and Spottiswoode, London. 